\title{
Association of Climatic Factors on Population Dynamics of Leaf Roller, Diaphania pulverulentalis Hampson (Lepidoptera: Pyralidae) in Mulberry Plantations of Sericulture Seed Farm
}

\author{
V. K. Rahmathulla, ${ }^{1}$ C. M. Kishor Kumar, ${ }^{1}$ B. S. Angadi, ${ }^{2}$ and V. Sivaprasad ${ }^{2}$ \\ ${ }^{1}$ P3 Basic Seed Farm, National Silkworm Seed Organization, Central Silk Board, Ring Road, Srirampura, Mysore, \\ Karnataka 570 008, India \\ ${ }^{2}$ Head Quarter, National Silkworm Seed Organization, Central Silk Board, Bangalore, India
}

Correspondence should be addressed to V. K. Rahmathulla, rahmathullavk@yahoo.co.in

Received 6 October 2011; Revised 27 November 2011; Accepted 30 November 2011

Academic Editor: Matilda Savopoulou-Soultani

Copyright ( $) 2012$ V. K. Rahmathulla et al. This is an open access article distributed under the Creative Commons Attribution License, which permits unrestricted use, distribution, and reproduction in any medium, provided the original work is properly cited.

\begin{abstract}
The production of quality mulberry leaf and subsequent production of quality silk is hampered due to the incidence of various insect pests. The present study analyses the population dynamics of Diaphania pulverulentalis (leaf roller), a serious pest of mulberry in a sericulture seed farm. The results indicated that maximum population buildup of the pest was recorded during rainy season. High humidity coinciding with low temperature because of southwest and northeast monsoon was conducive for breeding and multiplication of the pest. Correlation studies revealed that there was a significant negative correlation between increase in temperature and pest infestation. All other weather factors recorded from the study location have a positive correlation with incidence of the pest. The regression model developed also supported the relationship between the pest population buildup and weather factors.
\end{abstract}

\section{Introduction}

The existence and prosperity of sericulture industry depends upon the production of quality silk. For production of quality cocoon and silk, silkworm larva should feed with quality mulberry leaves, which is the exclusive food plant of the Bombyx mori $\mathrm{L}$. The process of mulberry leaf production is suffering due to the attack of various insect and noninsect pests. Being, a perennial blooming and high biomass producing plant with luxuriant growth under irrigated condition of recommended package and practices often leading to the breeding and multiplication of various pests. This condition leads to rapid pest proliferation, which resulted qualitative and quantitative loss of mulberry plants and ultimately low productivity in sericulture.

Diaphania pulverulentalis is one of the devastating pests of mulberry in southern states, namely, Andhra Pradesh, Karnataka, and Tamil Nadu. The pest reported from different locations of India (Nagaland [1]; Jammu [2]; Kashmir [3];
Punjab [4]) and the incidence reported from sericulture countries like China and Japan [5]. The early stages, larvae of the pest inhabits apical succulent portion of the shoot and leads to its destruction, resulting in stunted growth thereby affecting considerable decline in leaf yield about $12.8 \%$ with an average incidence of $21.77 \%[6,7]$. The incidence of pest occurs during June-February months and causing severe damage to young plantation and it affects severe loss in tender chawki leaves, which is very much essential for young age silkworm larvae. The infestation and population buildup of a pest is greatly affected by weather parameters like temperature, relative humidity, rainfall, and so forth. Climatic factors also have a dominating influence on the survival, development, and reproductive capacity of insect pests. In recent years, many pests and diseases have been reported to be the major limiting factors affecting the production of mulberry leaves due to intensive cultivation practices and indiscriminate use of nitrogenous fertilizers and pesticides. There is a change in the insect pest scenario 
in mulberry due to changes in climate and agro ecosystem. Besides, the above practices, the use of high-yielding varieties and monoculture also invited pest problems and minor pests have become major ones. Several workers studied the seasonal incidence of the pest and higher infestation was reported during October to February months in Krishnagiri $[8,9]$ and October to December in Salem areas of Tamil Nadu [10]. Since an understanding of the population dynamics of the pest species is vital for evolving appropriate and timely management strategies, the study was conducted to estimate the seasonal population variations of $D$. pulverulentalis in relation to climatic conditions. The present study was taken up in mulberry plantations of a Sericulture Basic Seed Farm about the population dynamics of leaf roller and seasonal incidence of the pest. The study results may bring out appropriate ecological requirements, particularly weather factors like temperature, relative humidity, and rainfall, that play a vital role in multiplication and distribution of insect pests, and these factors will give momentum to research on pest management strategies.

\section{Methodology}

2.1. Study Location. The study area P3 Basic Seed Farm is located in Mysore, Karnataka, India and it was situated at $12^{\circ} 18^{\prime} \mathrm{N} 76^{\circ} 39^{\prime} \mathrm{E}$ and has an average altitude of 770 meters $(2,526 \mathrm{ft})$. It is in the southern region of the state of Karnataka and spreads across an area of $128.42 \mathrm{~km}^{2}$. The summer season is from March to middle of June, followed by the monsoon season from the middle of June to October and the winter season from November to mid-February. The highest temperature recorded in Mysore was $38.5^{\circ} \mathrm{C}\left(101^{\circ} \mathrm{F}\right)$ and in winter, temperatures as low as $9.6^{\circ} \mathrm{C}\left(49^{\circ} \mathrm{F}\right)$. The average annual rainfall received was $798.2 \mathrm{~mm}$. The parental silkworm rearing at basic seed farm has to be organized in a manner to ensure that silkworm rearing is free from disease menace. Besides, these various cocoon characters and fecundity, have to be according to the norms fixed for each race. The mulberry garden has to be managed with due care and right input has to be added to produce healthy and succulent leaf.

2.2. Study Material. Diaphania pulverulentalis is a major pest of mulberry and it belongs to family Pyralidae. It was reported as a major pest of many agricultural and horticultural crops and lay about $80-150$ eggs on tender apical leaf buds of mulberry and hatching generally take place within 2-3 days. The larval stage, which causes severe damage to apical portion of the plant and the period, completes 8-12 days. The pupation takes place in the soil and the period takes 7-9 days. The adult longevities of 7-12 days and 9-14 days were recorded for male and female respectively. The target area of the leaf roller is the apical portion of the mulberry shoot. The young caterpillar binds the leaflets together with silky secretion, settles inside, and devours the soft tissues of the leaf surface and so the pest is popularly called as leaf roller or leaf webber. The web protects the larvae from natural enemies and even spraying of insecticide and killing the target pest become difficult. Late instar caterpillars feeds, on tender leaves and cause severe damage.

2.3. Host Plant. Mulberry (Morus sp.) is exclusive food for economically important silkworm (Bombyx mori L.), which is cultivated in tropical and temperate countries of the world. In India, it is cultivated mostly in the tropical region, evergreen throughout the year. Due to continuous crop improvement in the field of mulberry breeding and genetics, many new mulberry varieties have been evolved, much better than the local varieties in respect of quality and quantity of leaf produced. At the same time, these improvements paved ways for their susceptibility to be attacked by pests and diseases.

2.4. Sampling and Statistical Analysis. The mulberry garden of the basic seed farm was divided into six sub plots, and pruning schedule was adjusted to conduct six silkworm crops annually. Luxuriant growth and availability of different qualities such as tender, medium, and coarse leaves are assured throughout the year. For observations of pest incidence, ten plants from each subplots were selected at random. Thus, 60 plants were observed every week for a period of three years. The incidence of $D$. pulverulentalis was observed and the number of insects on each selected plant was counted and the total pest infestation was calculated. The data were tabulated in different months and the experiment was continued for three years (2008-2009, 2009-2010 and 2010-2011) and leaf roller infestation for each month was calculated. The weather factors like maximum temperature, minimum temperature, maximum humidity, minimum humidity, and rainfall data were recorded from the study location every day and month wise data were tabulated. The influence of weather factors on population density of leaf roller was analyzed by a simple correlation study and coefficients were worked out for a period of three years. In order to investigate the simultaneous influence of the climatic factors on pest incidence, a multiple linear regression analysis was accomplished.

\section{Results and Discussion}

3.1. Population Dynamics. The percentage of infestation varied in different months of the year, with a seasonal influence and a difference in the insect population in each year was observed. The three-year observation for the incidence of leaf roller indicated that during the year 2008-2009, mild infestation was started in the month of April $(0.56 \%)$ and an increase was recorded on subsequent months and after the onset of monsoon rain, the infestation was further intensified. The larval establishment severe damage was found during the months of June-October and the peak infestation was observed in September (39.56\%). After October infestation was gradually declined, and again a slight increase was recorded during December (17.86\%). This may be due to the unexpected cyclonic rainfall received, which resulted increase in relative atmospheric humidity and a further population buildup of the pest. During January, the infestation was lowest $(4.3 \%)$ and subsequent two 
TABLE 1: Leaf roller infestation during different months (percentage).

\begin{tabular}{|c|c|c|c|c|c|c|c|c|c|c|c|c|c|}
\hline Years & April & May & June & July & Aug. & Sept. & Oct. & Nov. & Dec. & Jan & Feb. & Mar. & Range of infestation \\
\hline 2008-09 & 0.56 & 12.45 & 32.56 & 38.56 & 31.78 & 39.56 & 38.45 & 12.78 & 17.86 & 04.3 & 0 & 0 & $0.56-39.56$ \\
\hline $2009-10$ & 0.36 & 16.45 & 32.66 & 39.46 & 35.78 & 40.16 & 39.35 & 11.78 & 06.76 & 02.3 & 0 & 0 & $0.36-40.16$ \\
\hline 2010-11 & 6.56 & 12.15 & 31.26 & 39.23 & 31.12 & 38.56 & 37.45 & 14.78 & 28.86 & 05.2 & 0 & 0 & $05.2-39.23$ \\
\hline Average & 2.49 & 13.68 & 32.20 & 39.08 & 32.89 & 39.43 & 38.42 & 13.11 & 17.83 & 03.93 & 0 & 0 & $2.49-39.43$ \\
\hline
\end{tabular}

TABLE 2: Association of climatic factors with leaf roller infestation during 3 years.

\begin{tabular}{|c|c|c|c|c|c|}
\hline Year & Maximum temperature & Minimum temperature & Maximum humidity & Minimum humidity & Rainfall \\
\hline 2008-09 & $-0.473^{* *}$ & $0.328^{*}$ & $0.594^{* *}$ & $0.584^{* *}$ & $0.396^{*}$ \\
\hline $2009-10$ & $-0.548^{* *}$ & $0.347^{*}$ & $0.741^{* *}$ & $0.835^{* *}$ & $0.378^{*}$ \\
\hline $2010-11$ & $-0.666^{* *}$ & $0.411^{* *}$ & $0.566^{* *}$ & $0.802^{* *}$ & $0.410^{*}$ \\
\hline Pooled & $-0.562^{* *}$ & $0.362 *$ & $0.633^{* *}$ & $0.740^{* *}$ & $0.395^{*}$ \\
\hline
\end{tabular}

** Significant at $1 \%$ level; ${ }^{*}$ Significant at $5 \%$ level.

months (February and March) infestation was zero. High temperature and low humidity prevailing during FebruaryMarch in the study location created an unfavorable ecological condition for the development and population buildup of leaf roller. Studied the infestation of leaf roller in dry areas of Chamaraj Nagar, Karnataka (India) and found that the infestation was recorded maximum during rainy season and least in summer [11]. However, some workers reported infestation was high during January [12, 13]. During 20092010 almost the same line of observations was made and the infestation was started at a low level during April (0.36\%) and it was recorded slightly higher in succeeding month (16.45\%) when compared with the previous year (Table 1 ). This may be due to the early showers received during the end of April. The trend was followed similar to the previous year and the infestation was increased during subsequent months until the commencement of the winter season. The peak infestation was recorded during September (40.16\%) and from November onwards infestation was marginally reduced. There was a rapid buildup of the pest population in the middle of each year beginning with June and ending in December. The influences of climatic factors on the incidence pest during different months are summarized in Figure 1. The peak relative humidity that occurred during AugustSeptember months influenced the highest incidence of the pest. The gradual decline in the population of leaf roller in January onwards was in consonance with the drop in the relative humidity.

During the year 2010-2011 the infestation of the leaf roller was started little early in April (Table 1) and higher infestation was recorded when compared with previous years $(6.56 \%)$. This is also may due to early rain fall received at the end of March and as a result a favorable climatic condition was created for population buildup of leaf roller in the field. Similar, to previous two years the population was recorded peak during June-October and highest infestation was recorded during the month of July (39.23\%). After October, during the beginning of the winter season there was a decline in population and again a slight increase was observed during the month of December $(28.86 \%)$ due to the unexpected cyclonic rainfall.

3.2. Correlation between Incidence of Pest Population and Abiotic Factors. The infestation of leaf roller showed a great sensibility to weather variations occurring over the period studied. A significant and negative correlation was observed between the percentage of leaf roller infestation and maximum temperature recorded from the study location $(r=-0.473$ in 2008-2009, $r=-0.548$ in 2009-2010, and $r=-0.666$ in 2010-2011). The study results were in accordance with the results of earlier workers [12]. The correlation coefficient data indicated that when the temperature rises up during the hottest months of FebruaryApril the infestation was recorded very low or nil (Table 2). However, a positive correlation was recorded between the infestation and minimum temperature. Similarly, correlation studies were worked out between infestation of leaf roller and maximum humidity, minimum humidity, and rainfall recorded during different months for a period of three years. All correlation coefficient $(r)$ data showed a positive correlation between the two variables. Significant $(P \leq 0.1)$ correlation was observed between maximum humidity and leaf roller infestation (0.594 in 2008-2009, 0.741 in 20092010 , and 0.566 in 2010-2011). The analysis also revealed a positive and highly significant correlation between leaf roller infestation and minimum humidity (0.584 in 2008-2009, 0.835 in 2009-2010, and 0.802 in 2010-2011). The results indicated that weather factors have greatest importance upon the population fluctuation of leaf roller. Quite a few workers reported similar results from Tamil Nadu climatic conditions $[13,14]$. The rainfall data of the study location also significantly correlated with leaf roller infestation $(0.396$ in 2008-2009, 0.378 in 2009-2010, and 0.410 in 2010-2011). The results of the analysis showed that due to continuous rain (June-October) naturally increased relative atmospheric humidity as well as percentage of soil moisture. It created a suitable condition for the luxuriant growth of mulberry and 


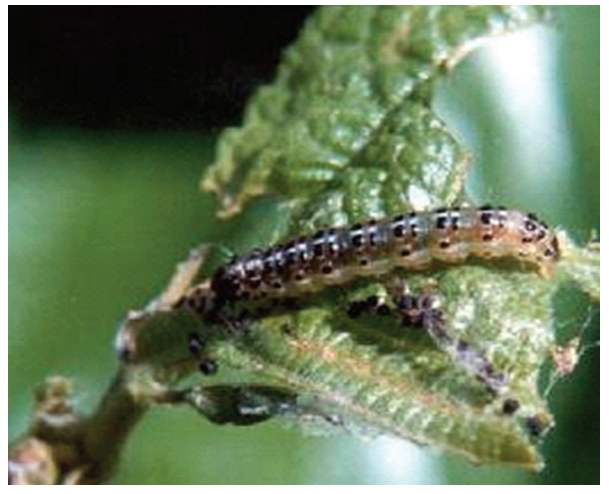

Larva of leaf roller

(a)

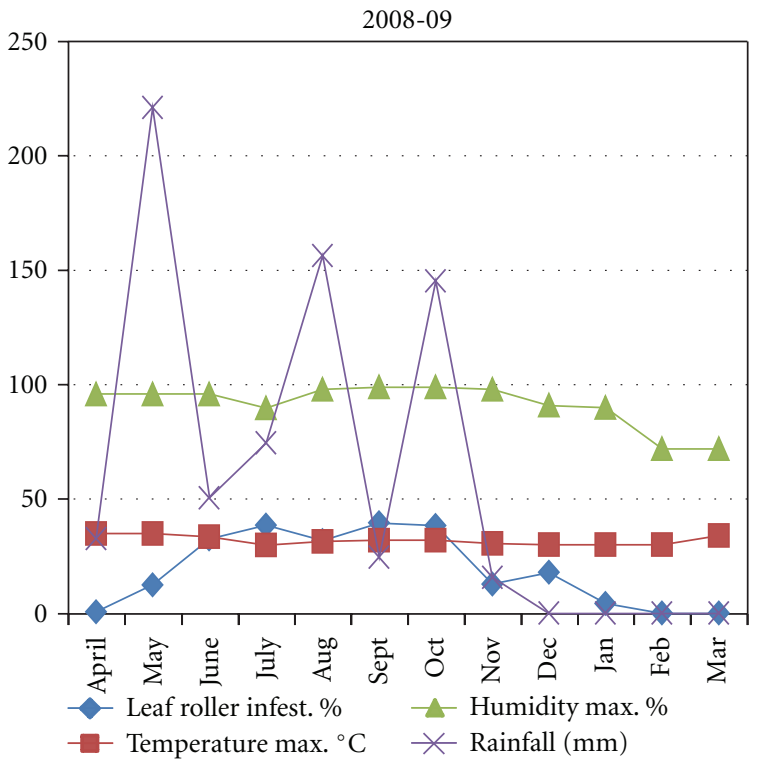

(c)

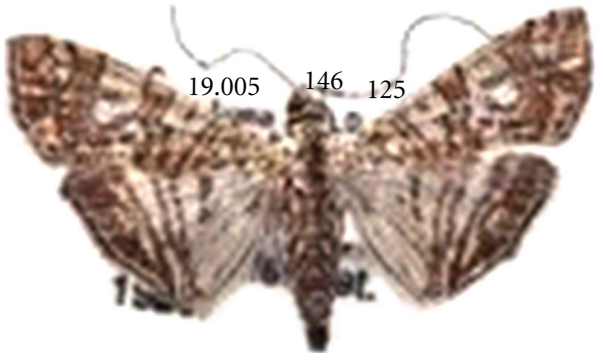

Adult moth of leaf roller

(b)

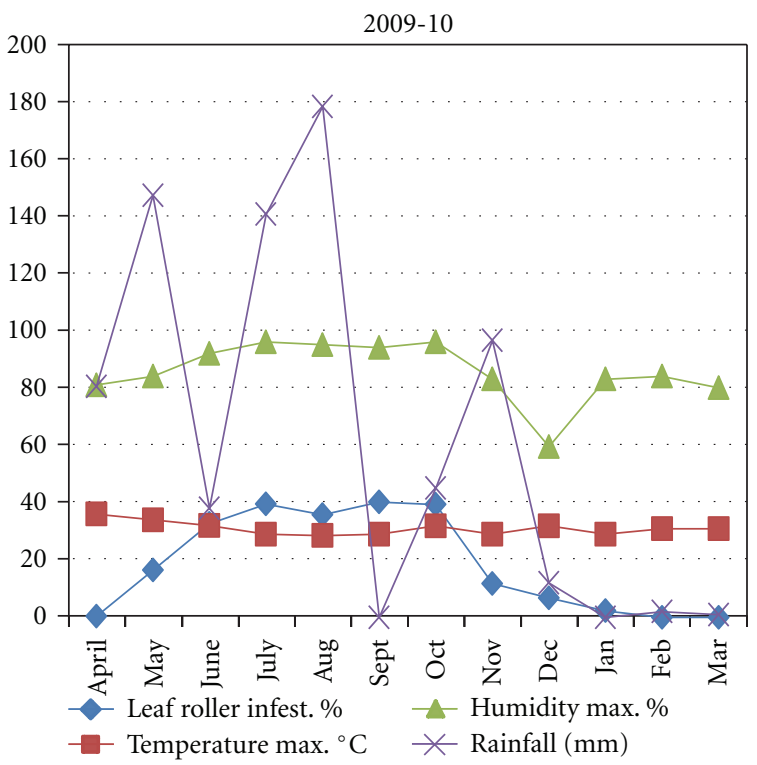

(d)

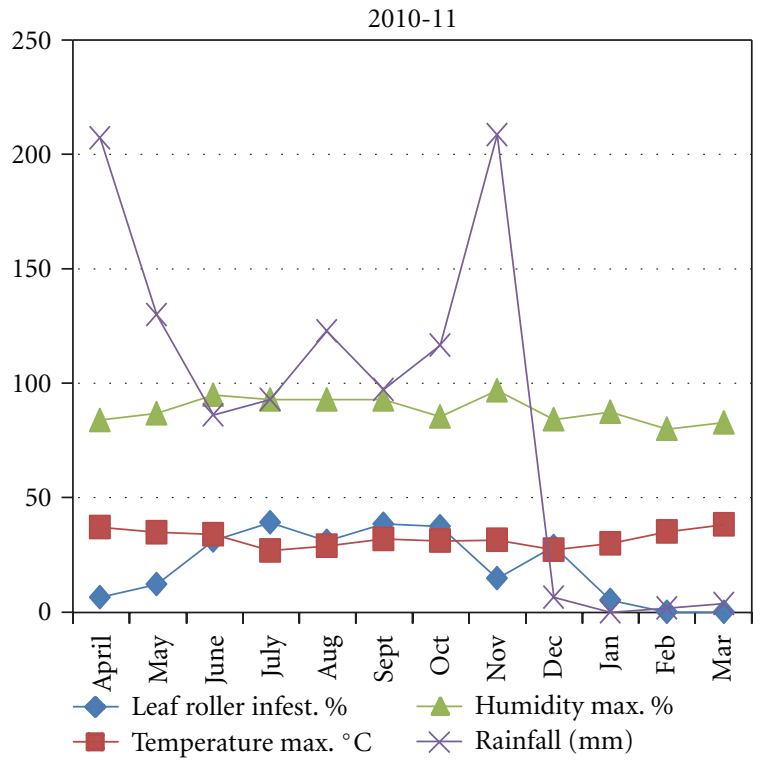

(e)

Figure 1: Association leaf roller (Diaphania pulverulentalis) infestation and abiotic factors of the study location (3-years period). 
TABLE 3: Regression model developed for Leaf roller infestation.

\begin{tabular}{lccccc}
\hline Years & $\begin{array}{c}\text { Maximum temperature } \\
(X 1)\end{array}$ & $\begin{array}{c}\text { Minimum } \\
\text { temperature }(X 2)\end{array}$ & $\begin{array}{c}\text { Maximum humidity } \\
(X 3)\end{array}$ & $\begin{array}{c}\text { Minimum humidity } \\
(X 4)\end{array}$ & Rainfall $(X 5)$ \\
\hline \multirow{2}{*}{$2008-09$} & $Y=-64.291+1.415 X 1$ & $Y=17.160-0.107 X 1$ & $Y=72.168-0.998 X 3$ & $Y=0.257-0.363 X 4$ & $Y=15.765-0.123 X 5$ \\
& $R^{2}=0.171^{*}$ & $R^{2}=0.190^{*}$ & $R^{2}=0.350^{*}$ & $R^{2}=0.281^{*}$ & $R^{2}=0.003$ \\
$2009-10$ & $Y=-99.537+2.605 X 1$. & $Y=17.370-2.012 X 2$ & $Y=87.908-1.245 X 3$ & $Y=-49.670-1.458 X 4$ & $Y=12.546-0.101 X 5$ \\
& $R^{2}=0.120^{*}$ & $R^{2}=0.122^{*}$ & $R^{2}=0.541^{* *}$ & $R^{2}=0.694^{* *}$ & $R^{2}=0.146$ \\
$2010-11$ & $Y=-110.883+2.798 X 1$. & $Y=06.104-1.492 X 2$ & $Y=122.281-1.661 X 3$ & $Y=12.542-0.321 X 4$ & $Y=14.431-0.165 X 5$ \\
& $R^{2}=0.441^{* *}$ & $R^{2}=0.173^{*}$ & $R^{2}=0.324^{*}$ & $R^{2}=0.641^{* *}$ & $R^{2}=0.055$ \\
\hline
\end{tabular}

** Significant at $1 \%$ level; ${ }^{*}$ Significant at $5 \%$ level.

availability of more nutritious and succulent leaves naturally favored a population buildup of leaf roller. Same results were observed and concluded the peak leaf roller infestation occurs both in southwest and northeast monsoon period, and showed that rainfall, and humidity were conducive for the multiplication of the pest [15]. However, maximum infestation was reported during the winter season in Kerala, (India) climatic condition [16]. These reports make it clear that there was a linear relationship of decreasing atmospheric temperature and increasing relative humidity with increased pest incidence. The significant correlation found between the leaf roller infestation and abiotic factors definitively help to develop a predictive model, by which the outbreak of this pest could be known in advance, so that timely control measures can be taken up to curtain the problem. The climate change can affect the response of insect pests to the host plants, although it is difficult to predict the impact of climate changes on various insect pests; the overall response is dependent on the impact of climate change on the insect, plant host and natural enemy relationship.

3.3. Regression Model. Linear regression analysis revealed that measured environmental variables have significant effects on leaf roller pest densities $(P<0.05)$ confirming results of correlation analysis. The importance of relative humidity and pest incidence for explaining significant portions of the independent variable for densities of leaf roller is also emphasized. The stepwise regression analysis constructed to investigate the abiotic factors contributed the most to the variance of the leaf roller population (Table 3). Regression analysis showed that minimum humidity recorded from the study location significantly contributed to the population variation of the pest (28\% in 2008-2009, $69 \%$ in 2009-2010, and 64\% in 2010-2011). Similarly, maximum humidity also significantly and positively contributed for variations in the population buildup $35 \%$ in 2008 $2009,54 \%$ in $2009-2010$, and $32 \%$ in $2010-2011$ ). Analysis also showed that the maximum temperature significantly and negatively contributed to the variation of leaf roller population $(17 \%, 12 \%$, and $44 \%$ for $2008-2009$, 20092010 and 2010-2011 resp.). The optimum regression model indicated the strong influence of maximum humidity and minimum humidity on variation in pest population in mulberry plantation. The forecast model can be used to predict the initiation and "red alert" season of the pest attack. This serves as a scale for the sericulturist to adopt effective crop protection measures at the appropriate time.

Timing of the insect pest appearance varies, depending on differences in temperature throughout the years, which makes the pest's forecasting and management difficult. One way to promote our understanding of the phrenology of Diaphania pulverulentalis is to develop a population dynamics model that explicitly incorporates temperaturedependent development. Indeed, models for temperaturedependent development of insect pests have been widely used as decision-support tools to improve the efficiency of pest management.

Forecasting the peak abundance of pest and diseases in advance helps in timely management of crop pests. The correlation and multiple regression analysis clearly showed the importance of weather factors in the pest incidence. Among the models regression can be used for forecasting the pest and also these models can be utilized in agroadvisories after validating with individual seasonal data.

\section{References}

[1] S. L. Gupta, "Check list of Indian Pyraustinae. (Lepidoptera : Pyralidae)," Memoirs of the Entomological Society of India, vol. 14, pp. 1-87, 1994.

[2] B. Sharma and J. S. Tara, "Insect pests of mulberry plants (Morus sp.) in Jammu region of Jammu and Kashmir state," Indian Journal of Sericulture, vol. 24, pp. 7-11, 1985.

[3] M. A. Dar, "Observation the biology of Glyphodes pyloalis Walker (Pyralidae: Lepidoptera) a serious pest of mulberry," The collection of papers of the II International Silk Conference, China, pp. 1-4, 1993.

[4] G. S. Mavi, J. S Bhalla, and A. S. Mann, "Glyphodes pyloalis Walker (Pyralidae: Lepidoptera) pest of mulberry-a new record in Punjab," Journal of Sericulture, vol. 4, no. 1, pp. 2829, 1996.

[5] G. Rangaswami, M. N Narasimhanna, K. Kasiviswanathan, C. R. Sastry, and M. S. Jolly, "FAO Sericulture Manual I Mulberry Cultivation,” Oxford \& IBH, Delhi, India, pp. 1-150, 1976.

[6] D. K. Siddegowda, V. K. Gupta, A. K. Sen et al., "Diaphania sp. Infests mulberry in south India," Indian Silk, vol. 34, no. 8, pp. 6-8, 1995.

[7] S. Rajadurai, A. K. Sen, D. Manjunath, and R. K. Datta, "Natural enemy fauna of mulberry leaf roller Diaphania pulverulentalis (Hampson) (Lepidoptera: Pyralidae) and it's 
potential," in Proceedings of the Seminar on Sericulture Technology: An Appraisal, p. 37, Central Sericultural Research and Training Institute, Karnataka, India, 2000.

[8] M. Muthulakshmi, P. Samuthiravelu, A. Suresh, and S. Jayaraj, "Studies on development of sustainable pest management in mulberry," in Sustainable Insect Pest Management, S. Ignacimuthu and S. Jayaraj, Eds., pp. 269-284, Narosa, Delhi, India, 2003.

[9] P. Samuthiravelu, L. Hemanthkumar, J. Ravikumar, S. Jayaraj, and S. M. H. Qadri, "Effects of non edible oil cakes on mulberry leaf production and incidence of key pests and their natural enemies," in Proceedings of the National Symposium on Recent Trends in Applied Biology, p. 87, Avinashilingam Institute for Home Science and Higher Education for Women, Tamil Nadu, India, January 2004.

[10] S. M. H. Qadri, S. Balasaraswathi, S. Masilamani, and T. Thirunavukkarasu, "Field testing of IPM package for the management of mulberry leaf webber Diaphania pulverulentalis (Hamp.)," in Sustainable Insect Pest Management, S. Ignacimuthu and S. Jayaraj, Eds., pp. 266-268, Narosa, Delhi, India, 2003.

[11] R. Gururaj and C. C. Choudhuri, "Epidemiology of leaf roller (Diaphania pulverulentalis) and its management through IPM in mulberry," in Proceedings of the National Seminar on Mulberry Sericulture Research in India, pp. 26-28, Karnataka State Sericulture Research and Development Institute, Karnataka, India, February 2001.

[12] R. S. Gowda, T. K. Narayanaswamy, and V. T. Sannaveerappanavar, "Seasonal incidence of mulberry leaf roller, Diaphania pulverulentalis (Hampson) (Lepidoptera: Pyralidae)," in Proceedings of the National Conference on Strategies for Sericulture Research and Development, p. 42, Central Sericultural Research and Training Institute, Karnataka, India, November 2000.

[13] S. S. Velavan, S. S. Subramanian, and M. Muthuswami, "Population dynamics of the mulberry leaf Webber, Glyphodes pulverulentalis (Hampson)," in Proceedings of the National Seminar on Emerging Trends in Pests and Diseases and their Management, p. 192, Centre for Plant Protection Studies Tamil Nadu Agricultural University, Tamil Nadu, India, October 2001.

[14] P. Samuthiravelu, M. Muthulakhsmi, A. Suresh, and S. Jayaraj, "Observations on biological, botanical and chemical control tactics of mulberry pest management," in Sustainable Insect Pest Management, S. Ignacimuthu and S. Jayaraj, Eds., pp. 285294, Narosa, Delhi, India, 2003.

[15] M. G. Bai and B. Marimadaiah, "Seasonal occurrence of the mulberry leaf-roller Diaphania pulverulentalis (Hampson) and its parasitoids," Entomon, vol. 27, no. 1, pp. 51-56, 2002.

[16] T. Philip and S. M. H. Qadri, "Seasonal Incidence of Leaf Webber, Diaphania pulverulentalis Hamps. On Mulberry in Kerala," International Journal of Plant Protection, vol. 2, no. 1, pp. 24-26, 2009. 

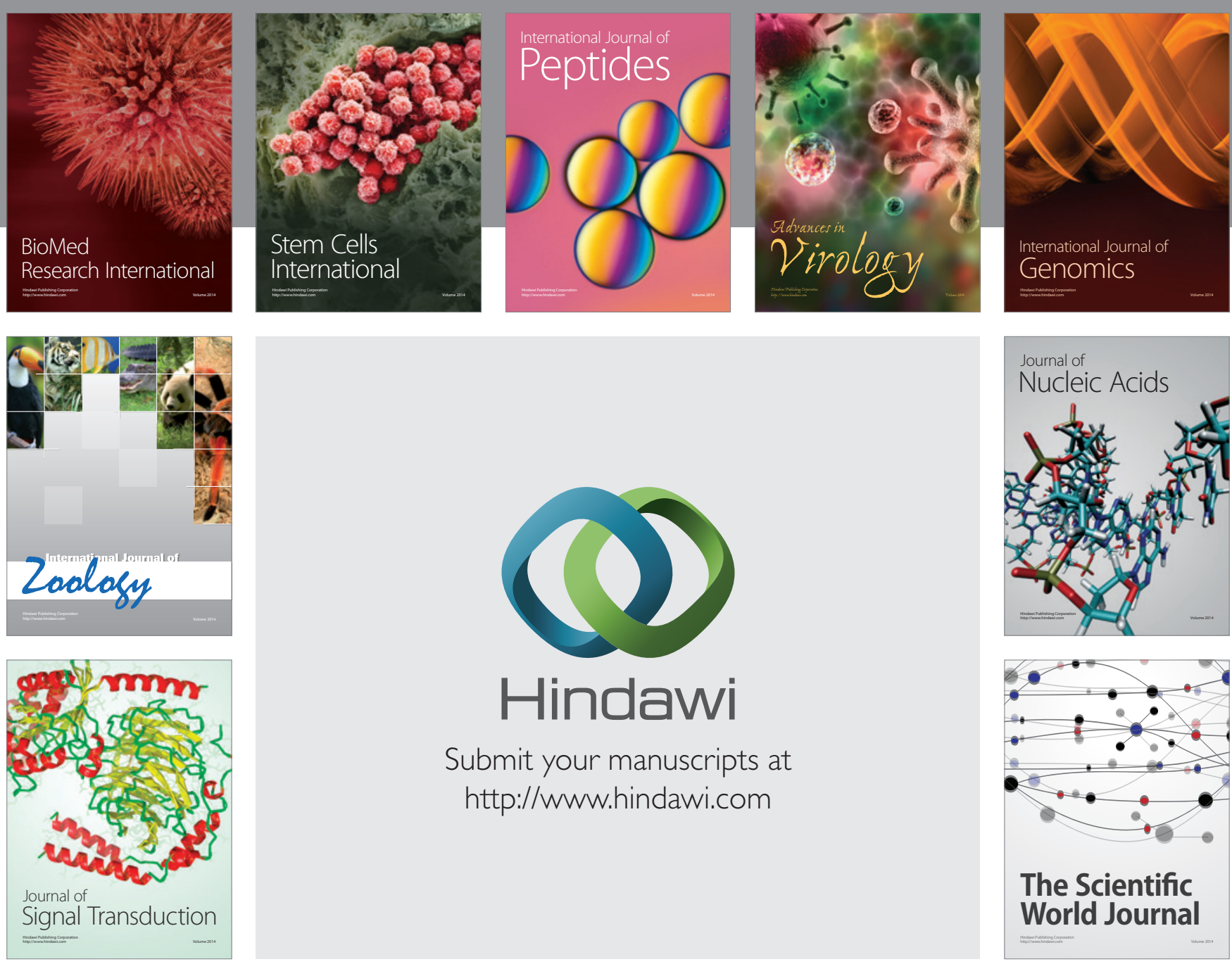

Submit your manuscripts at

http://www.hindawi.com
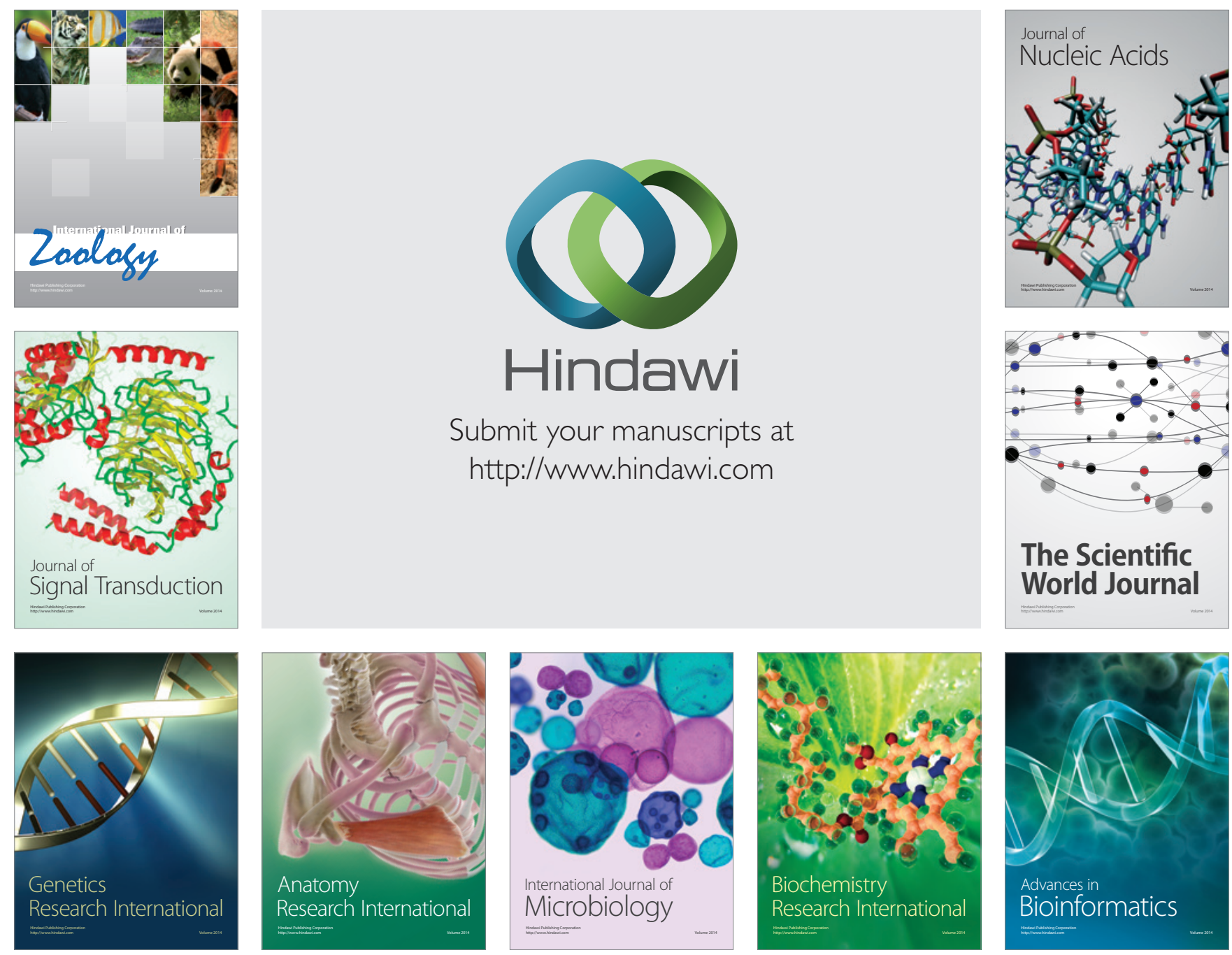

The Scientific World Journal
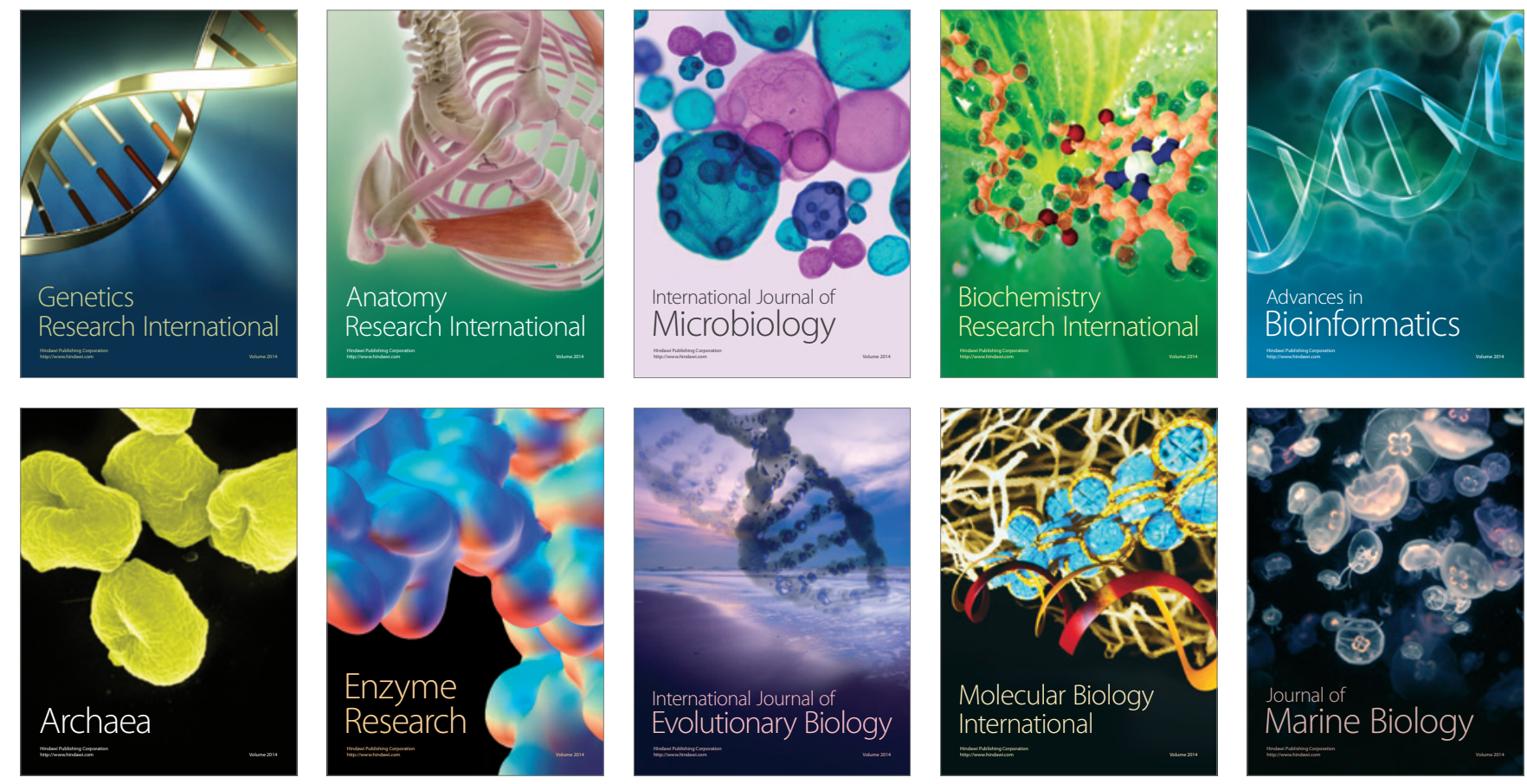